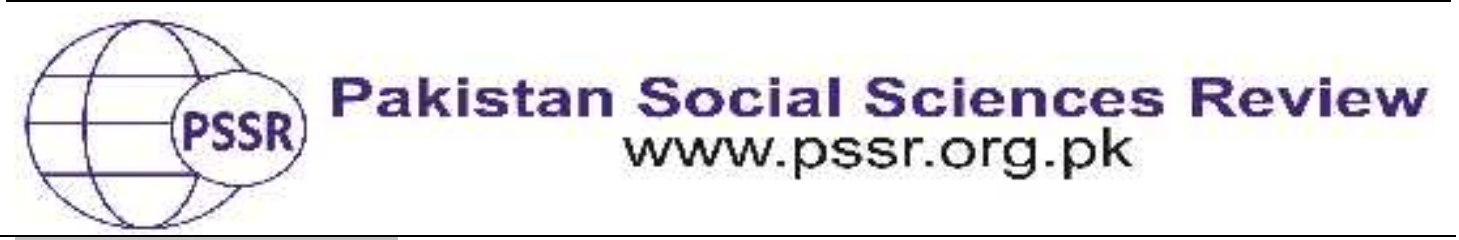

RESEARCH PAPER

\title{
A Study of Malnutrition Problem and its Relationship with Students' Reading and Writing Abilities at the Primary School Level in Tharparkar, Sindh, Pakistan
}

\author{
Dr. Tariq Bhatti 1 , Dr. Sumera Irum², Jameel Ahmed 3
}

1. Assistant Professor, Faculty of Education, University of Sindh, Jamshoro, Sindh, Pakistan

2. Assistant Professor, Faculty of Education, University of Sindh, Jamshoro, Sindh, Pakistan

3. Ph. D Scholar, Faculty of Education, University of Sindh, Jamshoro, Sindh, Pakistan

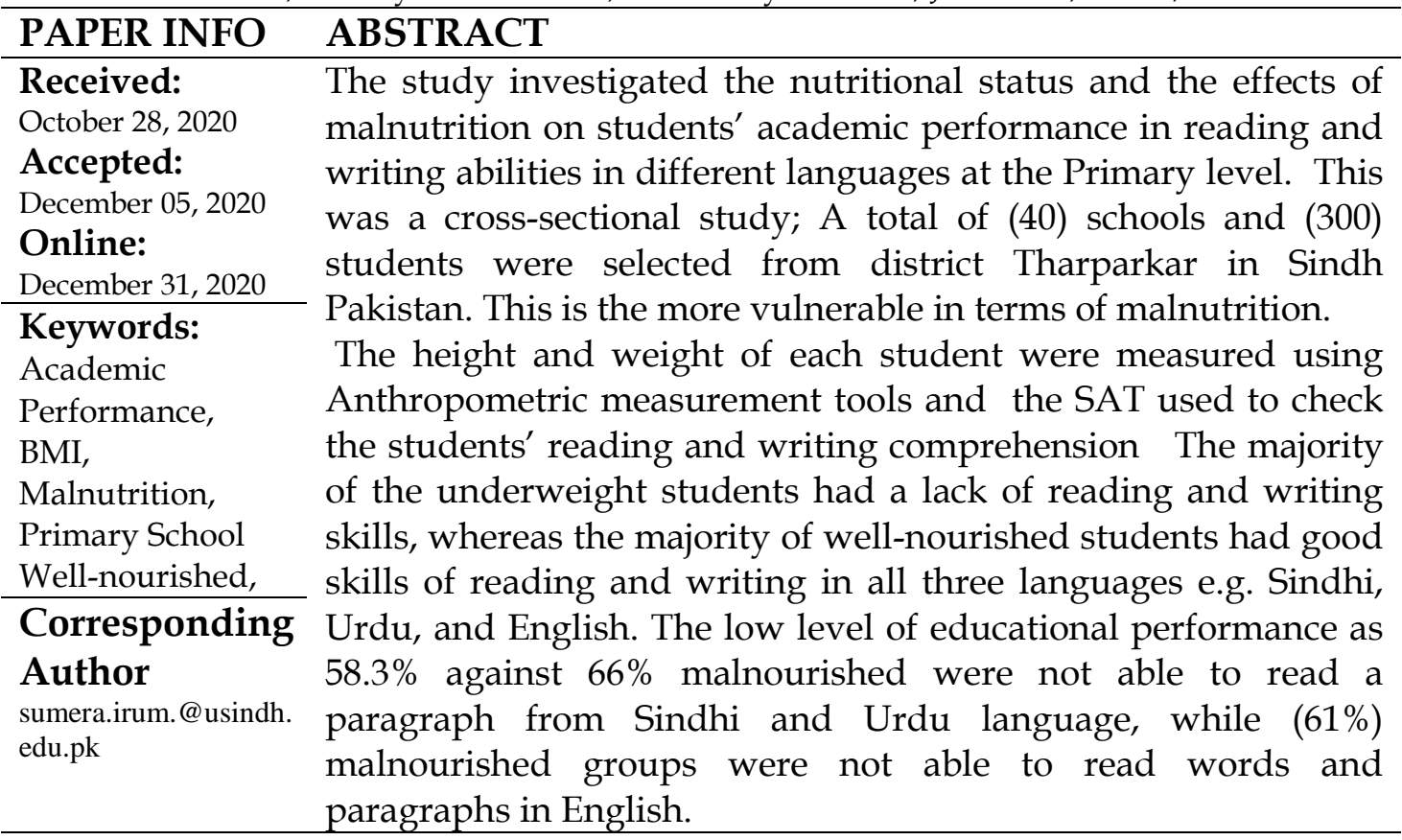

\section{Introduction}

Malnutrition is a general term that shows some or all nutritional food elements that are important for human health. Nutrition is required for all but school-age are the active growing phase of childhood who need proper attention in terms of their health. Primary school age is a dynamic period of physical growth as well as the mental development of the child. Research indicates that health problems due to miserable nutritional status occur in primary school-age children can cause within them low school enrolment, high absenteeism, early dropout, and unsatisfactory classroom performance (WHO, 2019). Malnutrition is a universal problem. Globally, (150) million children under 5 years old were stunted in (2017), 
while half of them live in Asia and one-third in Africa. Globally, 50.5 million children under 5 years old were squandered in 2017; two-thirds live in Asia and one quarter in Africa. Two out of five stunted 58.7 Million children and more than half of the wasted 26.9 Million children live in South Asia (WHO, 2019; Ahmad et al., 2020).

Pakistan observes a miserable condition for children. Nearly half of children $(49.8 \%)$ in Pakistan are stunted while $17.5 \%$ percent are wasted. It is found out that 72 percent of households are food insecure, 48.8 percent of the children under five are malnourished, $48 \%$ of children are stunted and 19.6 percent of children suffered from wasting - low weight for height in Sindh. In District Tharparkar 53\% of the total children are underweight about $45.9 \%$ are stunted and $29 \%$ are wasted (Khan \& Hancioglu, 2019). Globally at least 3.1 million children die due to malnutrition each year. 66 million primary school-age children attend classes hungry across the developing world, with 23 million in Africa alone (Nzoka \& Orodho, 2014; Govindan \& Soleimani, 2017). The following Table 1 shows different number of children having problem of malnutrition in the different countries.

Table 1

Current statistics of malnutrition at the global level

\begin{tabular}{ccc}
\hline Region/Country & $\begin{array}{c}\text { Childhood Stunting } \\
\text { under 5 years }\end{array}$ & $\begin{array}{c}\text { Childhood wasting } \\
\text { under 5 years }\end{array}$ \\
\hline World wide & 150 Million & 50.5 Million \\
\hline Africa & 58.7 Million & 13.8 Million \\
\hline Assia & 83.6 Million & 35.0 Million \\
\hline South Asia & 61.2 Million & 26.9 Million \\
\hline Pakistan & 12 Million $(49.8 \%)$ & $17.5 \%$ \\
\hline Sindh & $48 \%$ & $19.4 \%$ \\
\hline Tharparkar & $45.9 \%$ & $29 \%$ \\
\hline
\end{tabular}

Source: World Health Organization (2017) and Khan \& Hancioglu (2019)

Many research studies have been conducted showing the impact of malnutrition on students' academic performance. As Rashmi \& Shweta et.al (2017) were found a positive relationship between weight and height of the students based on their age and English as well as Math score, determined that the occurrence of undernourishment is high among students in private educational institutions also; and the dietary status of the students is powerfully interconnected with their educational abilities. This study has also proven an important association among numerous signs of nutritious status and instructive routine of students in English and Mathematics subjects. Another study was conducted by Chinyoka, in 2014. The researcher found that undernourishment exaggerated bodily growth, mental development and it consequently affects educational routine, well-being, and the 
existence of students. Undernourishment also extends scarcity because of bigger health caution prices. Further, the study also found that starving and malnourished students were not capable to take on bodily effort and sports events extremely. They were reluctant to attend an educational institution, however, if they attend school, they were not able to concentrate on learning (Chinyoka, 2014; Ahmad et al., 2020).

Sufficient food is the basic right of every human being. Poor nutrition is the main cause of the death of children in Pakistan. More than half of the deaths occurred due to malnutrition in Pakistan (Sindh BOS, 2014). Sindh province has one of the highest percentages of stunted and underweight children. District Tharparkar has also reported the highest percentage of child malnutrition in recent years. Malnutrition negatively affects children's ability to learn, Weak immune system risk of sickness and diseases due to malnutrition affects the cognitive and physical development of schoolgoing children at Tharparkar at the primary level. Based on the above-mentioned statements the area of study is prone to poor academic achievements year after year in Government Schools of District Tharparkar. School-going children in this area of study are regularly assigned difficult domestic duties, they walk long distances to school, they go and remained very often on empty stomachs, and have a difficult school curriculum to contact with, and their dietary status is compromised.

Additionally, some of these students at the primary level are beginning to enter youth, a growth stage when nutritional requirements need more than double due to enhanced growth. These factors may, therefore, result in unmet needs during this period leading to poor health, and consequently poor academic achievements(UNICEF, 2017). Therefore, the purpose of this study was to see the effects of malnutrition on the academic performance of the school children at the primary level in district Tharparkar. The following objective was set to see the effects of malnutrition on the academic performance of the children at the primary school level.

The following objectives of the study were formulated to explore the problem of malnutrition among the students. The first objective was to determine the nutritional status of the class 5th students studying in Government Primary Schools. And the second objective was to assess the effects of malnutrition on the primary school level students' cognitive competencies in terms of reading and writing ability in the Sindhi language, reading and writing ability in the Urdu language, and reading and writing ability in the English language.

\section{Material and Methods}

It was cross-sectional research and a quantitative survey method was adopted to explore the objectives of the study. The study was carried out in 7 union councils of District Tharparkar of Sindh Province, Pakistan. The population of this study has consisted of primary students (Co-education Schools) from grade-5. The purposive sampling method was applied in selecting schools of those UCs where the malnutrition problem was more vulnerable, while random sampling was used in the 
selection of students. 300 students were taken as samples randomly. Anthropometric measurement tools were used to measure the height and weight of the students of class five in their classroom according to the standard techniques of (World Health Organization, 2007). Body mass index for age (BMI) was taken according to the students' age Weight/Height to define the underweight normal and overweight. Age weight and height of the child were confirmed, then calculated and interpret accordingly. The weight was measured on a weight machine and the height was measured in measuring tape.

The formula of Body mass index: $\mathrm{BMI}=$ Weight $(\mathrm{Kg})$

$$
\text { (Height }(\mathrm{m})^{2}
$$

The second tool was the Students Achievement Test (SAT) adopted from the Annual Status of Education Report (ASER). (Annual Status of Education Report (ASER) 2016 Pakistan, 2017). SAT used to check the students' reading and writing comprehension and students labelled as $4=$ Story level child, $3=$ Sentences level child, $2=$ Word level child, and $1=$ Letter level in reading comprehension. The performance of class $5^{\text {th }}$ students in reading \& writing comprehension was examined and matched with their BMI and interpret accordingly.

\section{Results and Discussions}

There were total (375) students selected for the current study. However, the response rate was $80 \%$ (300) which consisted of a sample of $56.7 \%$ (170) boys and $43.3 \%$ (130) girls. To achieve the first objectives of the study students were assessed through anthropometric measurement tools in this regards the results of the nutritional status was measured with the help of BMI calculator. The age, weight, height, and Category of Malnutrition have been shown in the following tables. Table 2 , showing the age-wise distribution of the sample. The data in the Table.01 show that the mean age of respondents was 11.74 as showing in table 2 .

Table 2

Age of the students

\begin{tabular}{ccc}
\hline Age & Frequency & Percentage \\
\hline $8-9$ & 31 & $10.3 \%$ \\
\hline $10-11$ & 77 & $25.7 \%$ \\
\hline $12-13$ & 166 & $55.3 \%$ \\
\hline $14-15$ & 26 & $8.7 \%$ \\
\hline Total & 300 & $100.0 \%$ \\
\hline \multicolumn{3}{c}{} \\
\hline
\end{tabular}

Table No.03 is showing the weight wise distribution of the students in the sample. The finding demonstrated that the mean of the weight of the respondents was $29.83 \mathrm{~kg}$ as indicated asc calculated. 
Table 3

Weight of the students

\begin{tabular}{ccc}
\hline Weight in Kg & Frequency & Percentage \\
\hline $20-24 \mathrm{~kg}$ & 5 & $1.7 \%$ \\
\hline $25-29 \mathrm{~kg}$ & 210 & $70.0 \%$ \\
\hline $35-39 \mathrm{~kg}$ & 80 & $26.7 \%$ \\
\hline $45+\mathrm{kg}$ & 5 & $1.7 \%$ \\
\hline Total & 300 & $100.0 \%$ \\
\hline & Mean Weight $=29.83 \mathrm{SD}=5.02$ \\
\hline
\end{tabular}

Table No.04 is showing the height-wise distribution of the students in the sample. The finding demonstrated that the mean of the height of the respondents was $128.58 \mathrm{~cm}$ as calculated.

Table 4

Height of the students

\begin{tabular}{ccc}
\hline Height in c.m & Frequency & Percentage \\
\hline $120-124$ c.m & 1 & $0.3 \%$ \\
\hline $125-129$ c.m & 213 & $71.0 \%$ \\
\hline $130-134$ c.m & 80 & $26.7 \%$ \\
\hline $135-139$ c.m & 2 & $0.7 \%$ \\
\hline $140-144$ c.m & 4 & $1.3 \%$ \\
\hline Total & 300 & $100.0 \%$ \\
\hline & Mean Height $=128.58 \mathrm{SD}=2.81$ \\
\hline
\end{tabular}

Weight, height, and age are used to make the diagnosis of body mass index (BMI) which is categorized as underweight, normal, and overweight. No statistically significant difference occurred between boys and girls, with all pvalues $>0.05(71.3 \%)$ of the students of class five were underweight whereas $26.7 \%$ of students found normal. Table No.05 is showing the different categories of Malnutrition according to BMI. The finding demonstrated that the mean BMI of the respondents was 18.4 as demonstrating in table 5 .

Table 5

Category of Malnutrition (BMI $=\mathrm{kg} / \mathrm{m} 2)$

\begin{tabular}{ccc}
\hline Category of Malnutrition $(\mathrm{BMI}=\mathrm{kg} / \mathrm{m} 2)$ & Frequency & Percentage \\
\hline Underweight $(<16-18.5)$ & 213 & $71.0 \%$ \\
\hline Normal $(18.5-24.9)$ & 81 & $27.0 \%$ \\
\hline Overweight $(25.0-29.9)$ & 6 & $2.0 \%$ \\
\hline Total & 300 & $100.0 \%$ \\
\hline Mean BMI $=18.4 \mathrm{SD}=2.18$ & &
\end{tabular}


Objective 2: To assess the relationship of malnutrition with students' cognitive components of academic a. (Ability in reading the Sindhi Language)

$H_{01}$. There is no significant relationship of malnutrition with the reading abilities of the students studying in class 5 th at government primary schools of District Tharparkar.

The data in table 6 specified that there is a statistically significant link exist between malnutrition and ability in a reading of Sindhi language (chi-square with 6 degrees of freedom critical value is $=12.592$, ( $\mathrm{P}$-value is $=0.00)$ and Spearman correlation (rho is $=-.806$ ). In other words, the calculated value $241.235^{\mathrm{a}}$ is greater than the critical value 12.592; so, the null (H0) hypothesis is rejected.

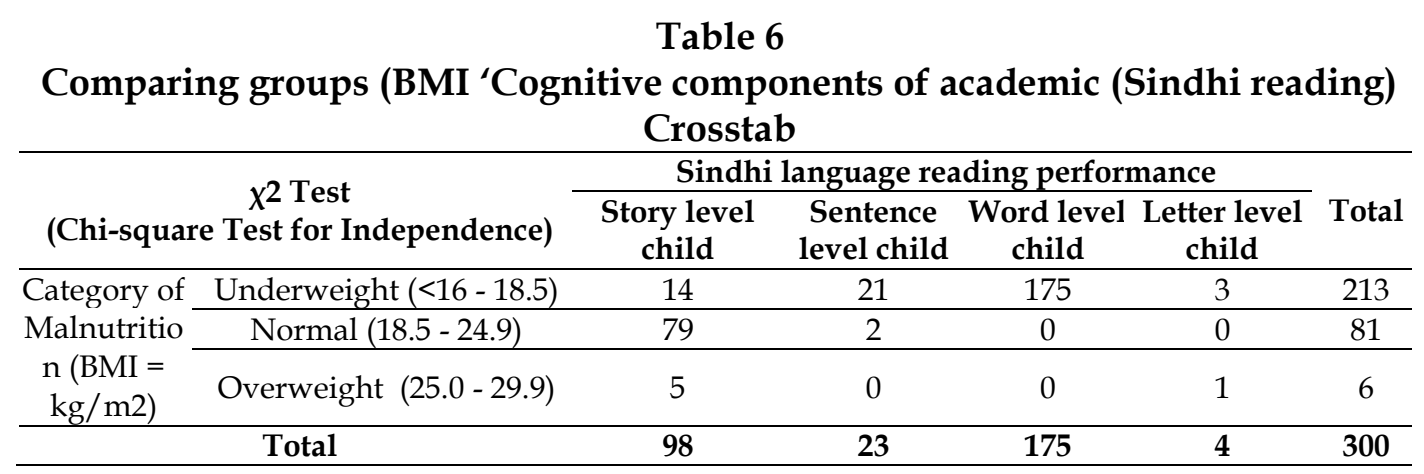

Figure 1. Showing the students competencies in Reading Sindhi Language as academic subject.

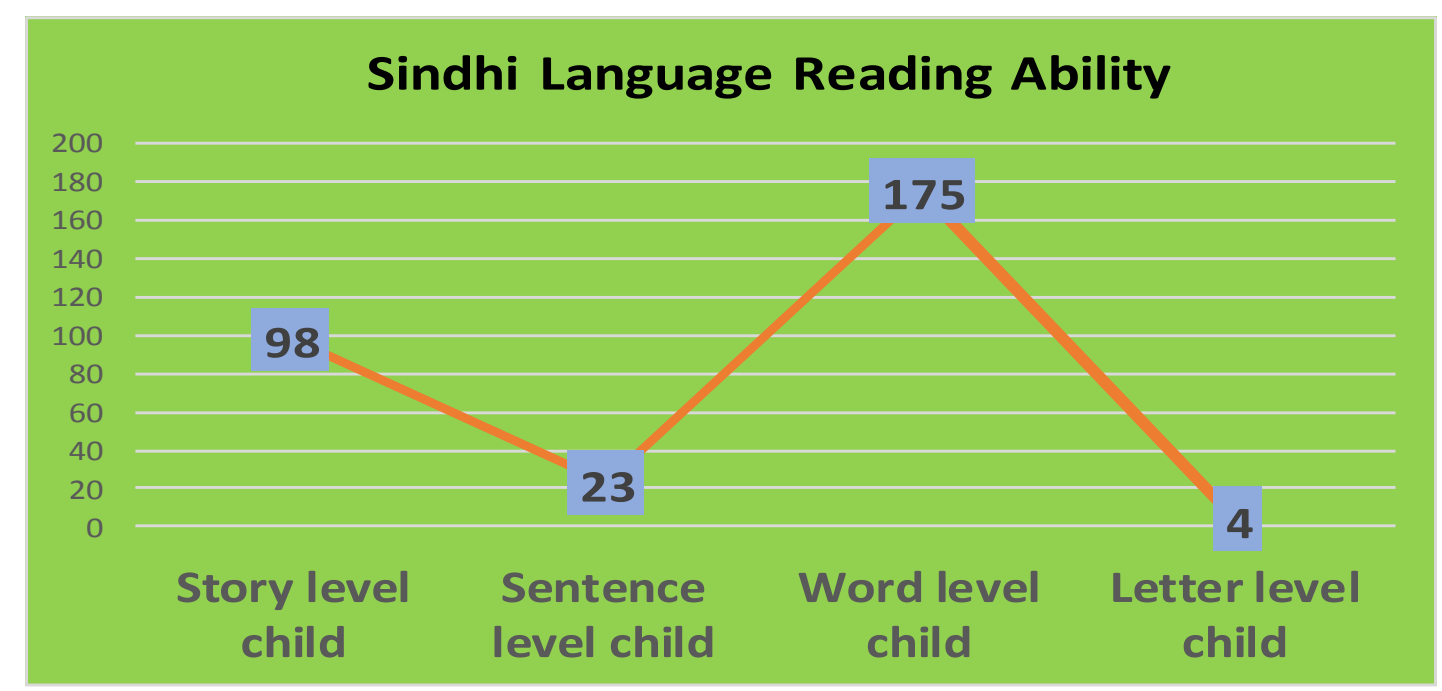

Objective 2: To assess the relationship of malnutrition with students' cognitive components of academics. (b. Ability in writing of Sindhi language) 
$H_{02}$. There is no significant relationship of malnutrition with the writing abilities of the students studying in class 5th at government primary schools of District Tharparkar.

Table 7

Comparing groups (BMI ‘Cognitive components of academic (Sindhi writing) Crosstab

\begin{tabular}{cccccc}
\hline \multirow{2}{*}{$\chi^{2}$ Test (Chi-square Test for Independence) } & \multicolumn{2}{c}{ Sindhi Language Writing Ability } & \multirow{2}{*}{$\begin{array}{c}\text { Low-Level Medium Level High-Level } \\
\text { Child }\end{array}$} & Total \\
& & Child & Child & \\
\hline \multirow{2}{*}{$\begin{array}{c}\text { Category of } \\
\text { Malnutrition (BMI } \\
=\mathrm{kg} / \mathrm{m} 2)\end{array}$} & Underweight $(<16-18.5)$ & 175 & 19 & 19 & 213 \\
\cline { 2 - 5 } & Normal $(18.5-24.9)$ & 0 & 47 & 34 & 81 \\
\hline & Overweight $(25.0-29.9)$ & 1 & 1 & 4 & 6 \\
\hline & Total & $\mathbf{1 7 6}$ & $\mathbf{6 7}$ & $\mathbf{5 7}$ & $\mathbf{3 0 0}$ \\
\hline
\end{tabular}

Figure 2. Showing the students competencies in writing Sindhi Language as academic subject.

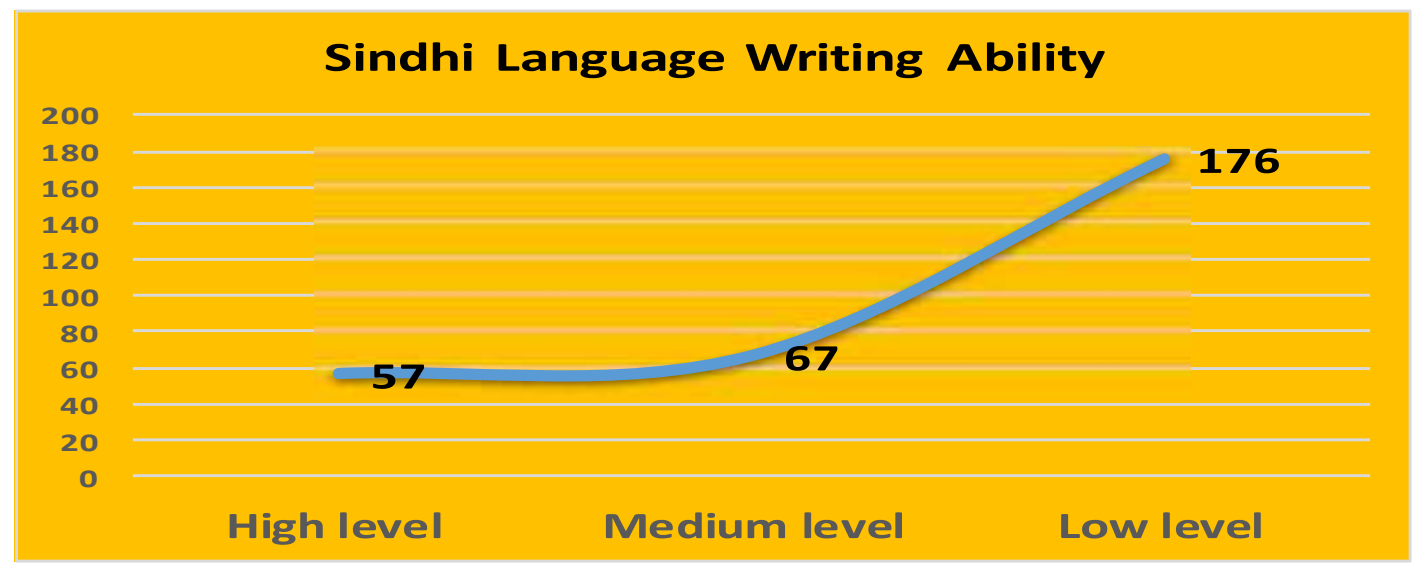

The data in table 7 showed that there is a statistically significant connection that exists in the malnutrition and Sindhi language writing ability (chi-square with 4 degrees of freedom the critical value is $=\mathbf{1 2 . 5 9 2}$, Spearman correlation rho $=\mathbf{- . 8 2 0}$ ). In other words, the computed value $\mathbf{1 7 3 . 8 7 8}^{\mathrm{a}}$ is larger than the critical value 12.592; therefore, the null hypothesis is rejected.

Objective 2: To assess the relationship of malnutrition with students' cognitive components of academics. (c. Ability in reading the English Language)

$H_{03}$. There is no significant relationship of malnutrition with the reading abilities of the students studying in class 5 th at government primary schools of District Tharparkar. 
Table 8

Showing Comparing groups (BMI ‘Cognitive components of academic (English reading) Crosstab

\begin{tabular}{|c|c|c|c|c|c|c|}
\hline \multirow{2}{*}{\multicolumn{2}{|c|}{$\begin{array}{c}x^{2} \text { Test (Chi-square Test for } \\
\text { Independence) }\end{array}$}} & \multicolumn{4}{|c|}{ English language reading Ability } & \multirow[b]{2}{*}{ Total } \\
\hline & & $\begin{array}{l}\text { Story level } \\
\text { child }\end{array}$ & $\begin{array}{l}\text { Sentence } \\
\text { level child }\end{array}$ & $\begin{array}{l}\text { Word level } \\
\text { child }\end{array}$ & $\begin{array}{l}\text { Letter level } \\
\text { child }\end{array}$ & \\
\hline \multirow{3}{*}{$\begin{array}{c}\text { Category of } \\
\text { Malnutrition (BMI } \\
=\mathrm{kg} / \mathrm{m} 2)\end{array}$} & $\begin{array}{c}\text { Underweight }(<16- \\
18.5)\end{array}$ & 6 & 17 & 7 & 183 & 213 \\
\hline & Normal (18.5 - 24.9) & 3 & 65 & 13 & 0 & 81 \\
\hline & $\begin{array}{c}\text { Overweight }(25.0- \\
29.9)\end{array}$ & 0 & 5 & 1 & 0 & 6 \\
\hline \multicolumn{2}{|c|}{ Total } & 9 & 87 & 21 & 183 & 300 \\
\hline
\end{tabular}

Figure 3. Showing the students competencies in reading English Language as academic subject.

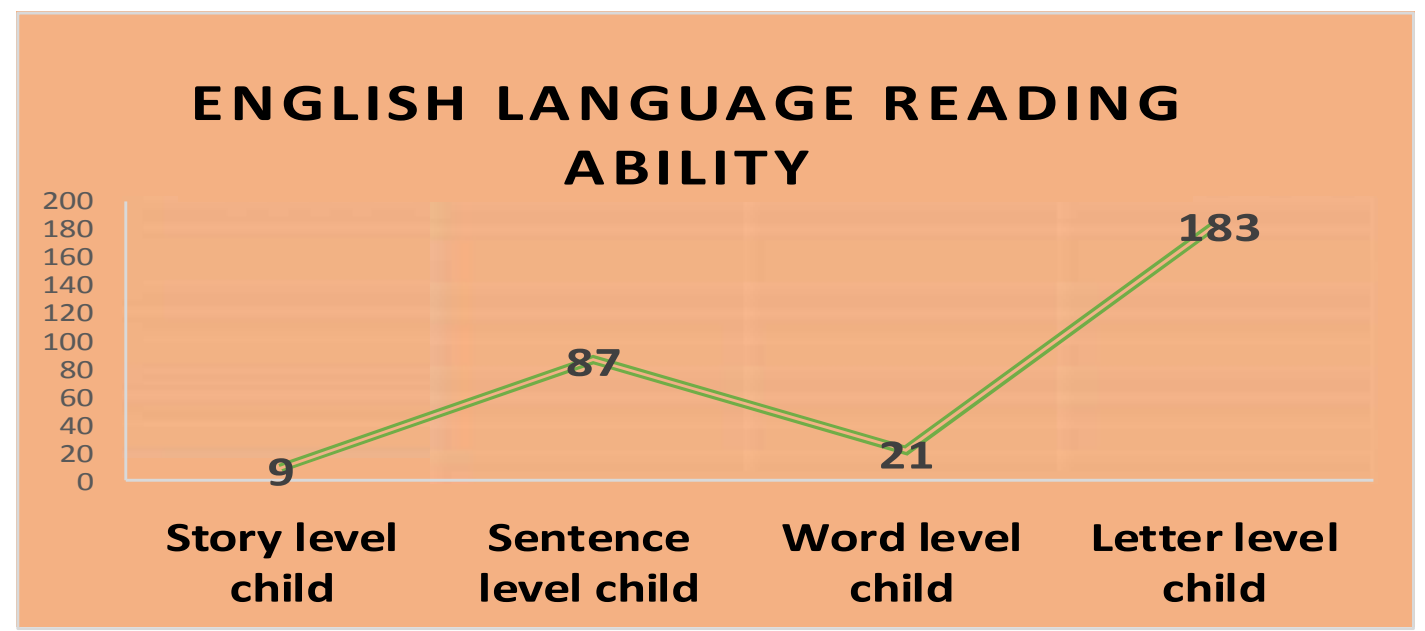

The data in Table 8 demonstrated that there is a statistically significant consequence that exists among the malnutrition and English language reading abilities (chi-square with 6 degrees of freedom the critical value is $=12.592$, a $p$-value is $=0.00$, and Spearman correlation rho $=$ is -.980). In other words, the computed value $\mathbf{2 0 1 . 4 6 8}{ }^{a}$ is larger than the critical value 12.592; therefore, the null hypothesis is rejected.

Objective: To assess the relationship of malnutrition with students' cognitive components of academics. (d. Ability in writing the English Language)

$H_{04}$. There is no significant relationship of malnutrition with the reading abilities of the students studying in class 5 th at government primary schools of District Tharparkar. 
Table 9

Comparing groups (Malnutrition' Performance in writing the English language)

Crosstab

\begin{tabular}{clccccc}
\hline \multirow{2}{*}{$\mathbf{2}$ Test (Chi-square Test for Independence } & \multicolumn{2}{c}{$\begin{array}{c}\text { English Language Writing Ability } \\
\text { Low-Level } \\
\text { Child }\end{array}$} & $\begin{array}{c}\text { Medium Level } \\
\text { Child }\end{array}$ & $\begin{array}{c}\text { High-Level } \\
\text { Child }\end{array}$ & Total \\
\hline $\begin{array}{c}\text { Category of } \\
\text { Malnutrition }\end{array}$ & Underweight $(<16-18.5)$ & 201 & 9 & 3 & 213 \\
\cline { 2 - 5 }$(\mathrm{BMI}=\mathrm{kg} / \mathrm{m} 2)$ & Normal $(18.5-24.9)$ & 23 & 39 & 19 & 81 \\
\cline { 2 - 5 } & Overweight $(25.0-29.9)$ & 4 & 2 & 0 & 6 \\
\hline & Total & $\mathbf{2 2 8}$ & $\mathbf{5 0}$ & $\mathbf{2 2}$ & $\mathbf{3 0 0}$ \\
\hline
\end{tabular}

Figure 4. Showing the students competencies in writing English Language as academic subject.

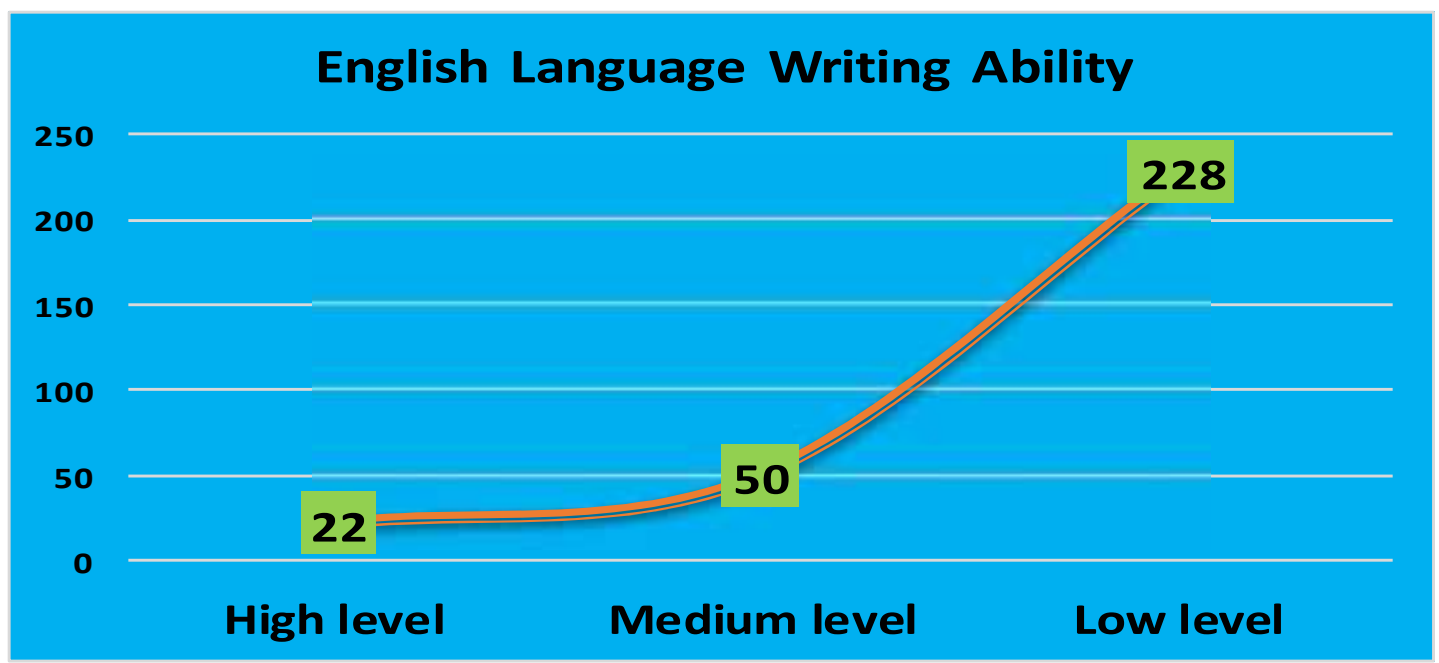

The data in table 9 showed that there is a statistically significant connection that exists between malnutrition and English language writing performance (chisquare with 4 degrees of freedom the critical value is $\mathbf{9 . 4 8 8}$, a p-value is 0.00 and the correlation is rho $=-\mathbf{9 1 1}$ ). In other words, the calculated value $141.975^{\mathrm{a}}$ is larger than the critical value 9.488; therefore, the null hypothesis is rejected.

Objective: To assess the relationship of malnutrition with students' cognitive components of academics. (e. Ability in reading the Urdu Language)

$H_{05}$. There is no significant relationship of malnutrition with the reading abilities of the students studying in class 5 th at government primary schools of District Tharparkar. 


\section{Table10}

Comparing groups (BMI ‘Cognitive components of academic (Urdu reading)

\section{Crosstab}

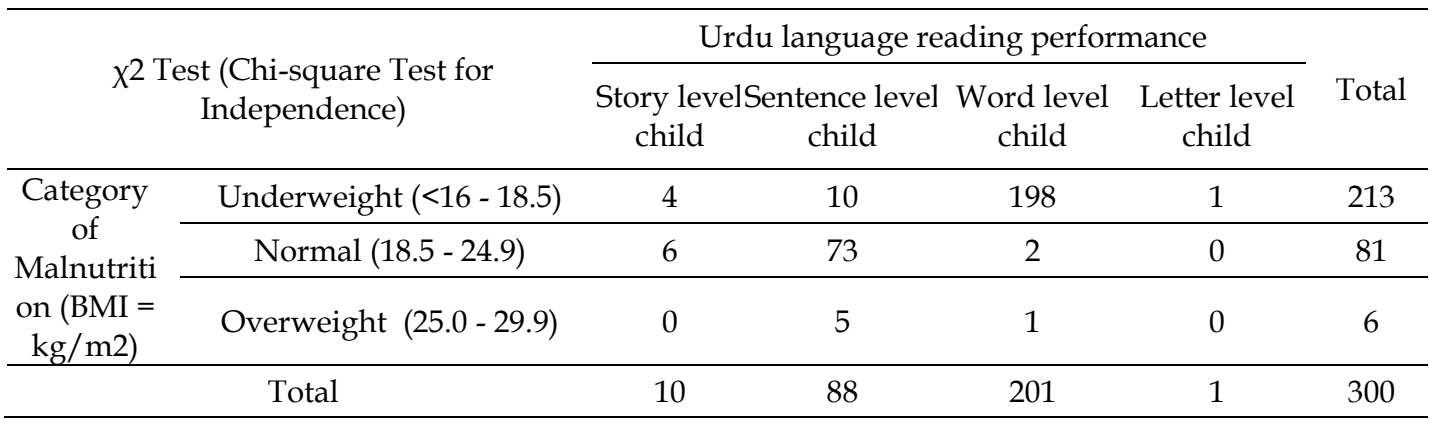

Figure 5. Showing the students competencies in reading Urdu Language as academic subject.

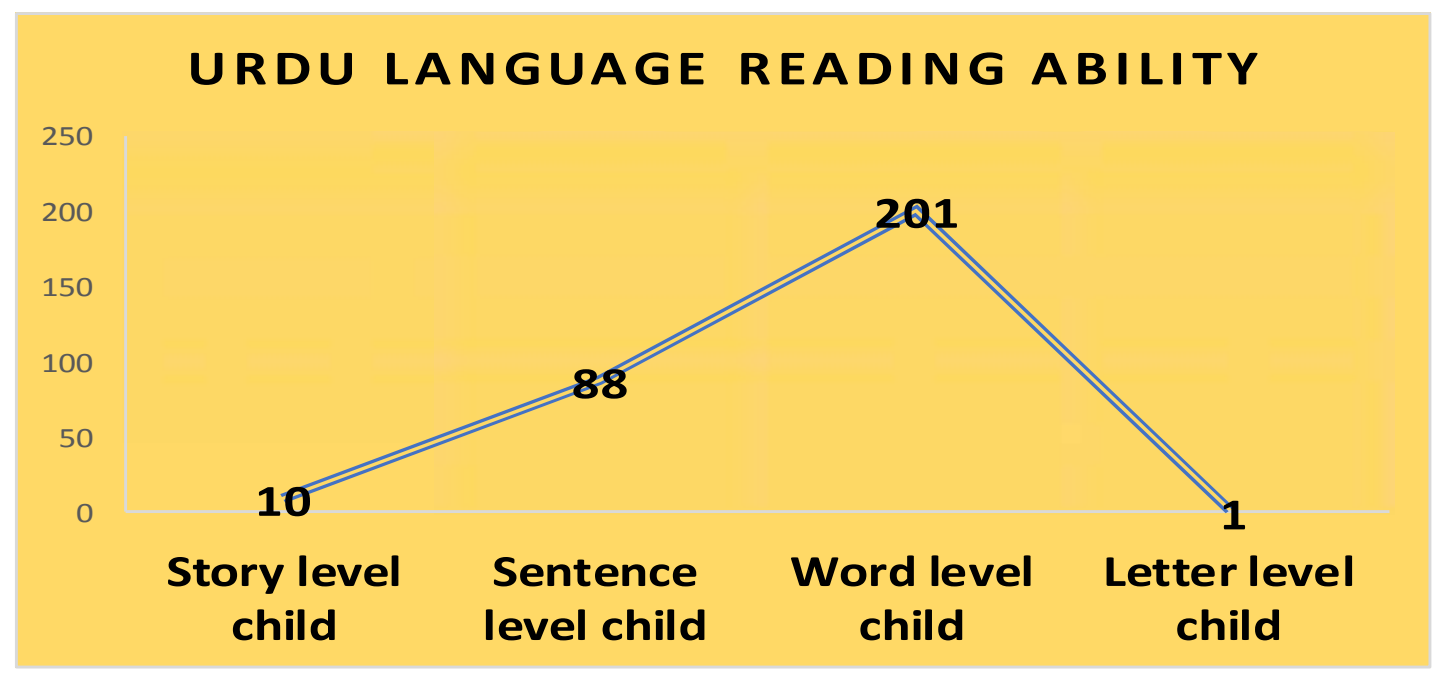

The data in table 10 specified that there is a statistically significant association that exists concerning malnutrition and Urdu language reading performance. (Chi-square with 6 degree of freedom the critical value is $=12.592, \mathrm{P}$ value is 0.00 and the spearman correlation rho $=-.931)$. In other words, the computed value 232.118 a is larger than the critical value 12.592 ; therefore, the null hypothesis is rejected.

Objective: To assess the relationship of malnutrition with students' cognitive components of academic (f. ability in writing the Urdu Language)

$H_{o 6}$. There is no significant relationship of malnutrition with the reading abilities of the students studying in class 5 th at government primary schools of District Tharparkar. 
The data in table 11 specified that there is a statistically significant connection that exists between malnutrition and Urdu language writing ability. (Chi-square with 4 degree of freedom the critical value $=9.488$, p-value is 0.00 and Spearman correlation rho is $=.777)$. In other words, the calculated value 187.954a is greater than the critical value 9.488; so, H0: the null hypothesis is rejected. Table.8 shows the comparing groups (BMI 'Cognitive components of academic (English reading) Crosstab.

Table 11

Comparing groups (Malnutrition' Performance in writing the Urdu language) Crosstab

\begin{tabular}{|c|c|c|c|c|c|}
\hline \multirow{2}{*}{\multicolumn{2}{|c|}{$\begin{array}{c}x^{2} \text { Test (Chi-square Test for } \\
\text { Independence) }\end{array}$}} & \multicolumn{3}{|c|}{ Urdu Language Writing Ability } & \multirow[b]{2}{*}{ Total } \\
\hline & & $\begin{array}{l}\text { Low-Level } \\
\text { Child }\end{array}$ & $\begin{array}{l}\text { Medium Level } \\
\text { Child }\end{array}$ & High-Level Child & \\
\hline \multirow{3}{*}{$\begin{array}{c}\text { Category of } \\
\text { Malnutrition } \\
(\mathrm{BMI}=\mathrm{kg} / \mathrm{m} 2)\end{array}$} & $\begin{array}{c}\text { Underweight }(<16 \\
18.5)\end{array}$ & 199 & 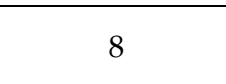 & 6 & 213 \\
\hline & Normal (18.5 - 24.9 & 11 & 38 & 32 & 81 \\
\hline & $\begin{array}{c}\text { Overweight }(25.0- \\
29.9)\end{array}$ & 1 & 3 & 2 & 6 \\
\hline \multicolumn{2}{|r|}{ Total } & 211 & 49 & 40 & 300 \\
\hline
\end{tabular}

Figure 6. Showing the students competencies in writing Urdu Language as academic subject.

\section{URDU LANGUAGE WRITING ABILITY}

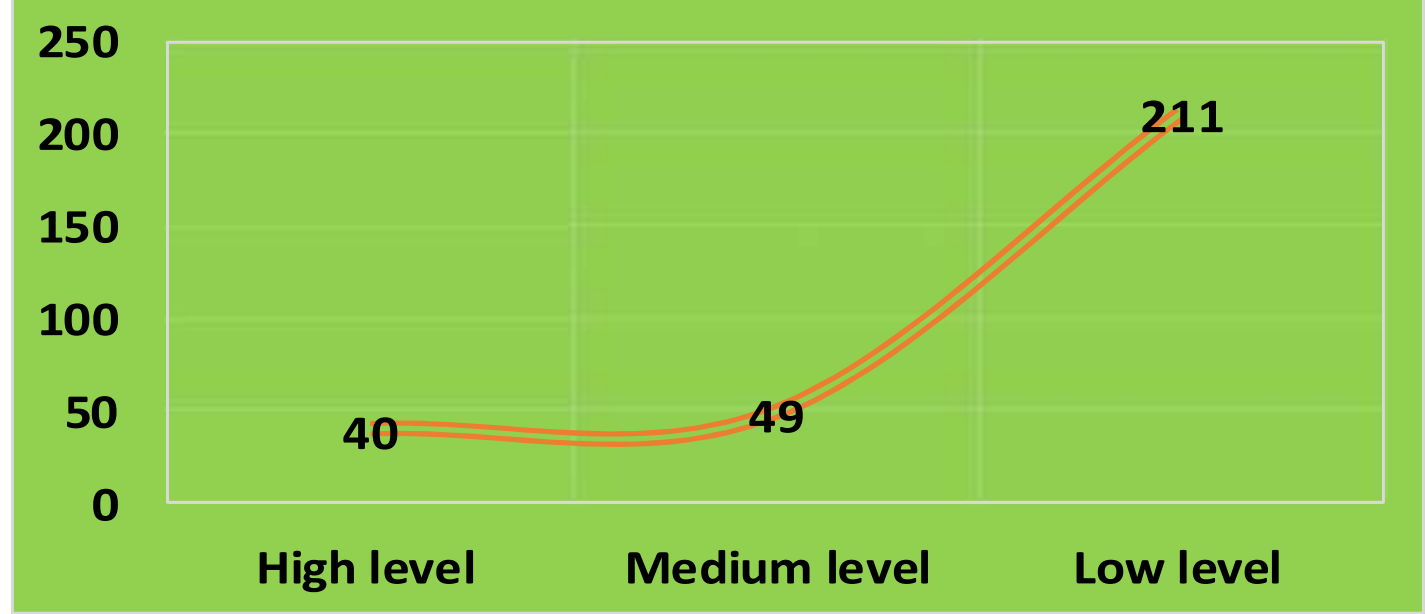

\section{Discussions}

The student achievement test regarding the reading and writing comprehension of 3 languages e.g. Sindhi, Urdu, and English is taken from 300 students of 40 different schools from the selected UCs of district Tharparkar. The first fact that is revealed from this student achievement test is that majority of 
students were not able to read a passage from the Sindhi, Urdu, and English language. When students are asked to read the passage loudly so that their reading speed and word-recognition can be checked, varying results were found. Only a small number of students were able to read the passage fluently and to pronounce it accurately and fluently. A large number of students are not able to read fluently; many are not able to pronounce or read some words and many students cannot write even a single well-structured sentence from these three languages. The reason behind this fact comes to know on investigating that students BMI score comes in the underweight category and their food consumption is not up to the standard level which is recommended by the health department. The results vary of those students whose BMI Score comes under the normal category those students were able to read and write paragraphs and sentences from the Sindhi language but some of them were also found weak in writing Urdu and English passages. Good reading and writing skills are dependent on the nutritional status of the students. The research study variables highlighted earlier specify the close dependence on each other. Therefore it is concluded that without proper nutrition the understanding of good academic performance is not possible.

A similar study was carried out by Rausch (2013). The investigation illustrates that consuming a fit, well-adjusted food progresses brain ability, makes the best use of cognitive competencies, and advances educational presentation in school-going, students. The outcomes of this research study originated that $(72 \%)$ of students with iron deficiency recorded a lower average in math, whereas only (50\%) of children with regular iron levels did well.

\section{Conclusion}

The research study concluded that well diet leads to the improved academic performance of students. When students consume appropriate meals according to the standard national health guidelines then children perform in a better way in physical and mental activities. A serious increase in underweight and malnourished children is due to scarcity, low literacy, big families, nourishment insecurity, and parental negligence. Students who are provided with a good and balanced diet are more likely to have the capacity to focus on learning lessons as compare to the hungry ones. When students experience food deficiencies, their intellectual, cognitive, and responsiveness conditions are different, which can affect negatively students' mental growth. Hence, there is a need for economic, political, and social changes as well as changes for personal advancement mainly through educational opportunities to improve the nutritional status of the children.

\section{Recommendations}

- The state government should focus on educating the people about smaller families along with subsidies. 
- It is the responsibility of the state, the corporate sector, the philanthropists, and the more fortunate in society, to break the vicious cycle of poverty, illiteracy, and ill-health and make the children contributing members of society in the future.

- Government and NGOs should start the Nutrition Programs in the villages and particularly in schools Subsidies should be given on the food items

- Adult literacy programs should be arranged which focus on the nutrition status of mothers and children at the local levels in the villages as parents can learn and gain knowledge about the nutrition of the children. 


\section{References}

Ahmad, I., Abdullah, N., Yuzir, A., Koji, I., \& Mohamad, S. E. (2020). Efficacy of microalgae as a nutraceutical and sustainable food supplement. In $3 r d$ ICA Research Symposium (ICARS) 2020 (p. 6).

Annual Status of Education Report (ASER) 2016 Pakistan. (2017). south Asian forum for educational development.

Chinyoka, K. (2014). Impact of Poor Nutrition on the Academic Performance of Grade Seven learners: A Case of Zimbabwe. International Journal of Learning and Development, 4(3), 73.

Khan, S., \& Hancioglu, A. (2019). Multiple indicator cluster surveys: delivering robust data on children and women across the globe. Studies in family planning, 50(3), 279-286.

Govindan, K., \& Soleimani, H. (2017). A review of reverse logistics and closed-loop supply chains: a Journal of Cleaner Production focus. Journal of Cleaner Production, 142, 371-384.

Nzoka, J. T., \& Orodho, J. A. (2014). School management and students' academic performance: How effective are strategies being employed by school managers in secondary schools in Embu North District, Embu County, Kenya. International Journal of Humanities and social science, 4(9), 86-99.

Resilience, B. (2017). The State Of Food Security And Nutrition In The World. Rome: Building resilience for peace and food security.

Rashmi, M. R., Shweta, B. M., Fathima, F. N., Agrawal, T., Shah, M., \& Sequeira, R. (2017). Prevalence of Malnutrition and Relationship with Scholastic Performance among Primary and Secondary School Children in Two Select Private Schools in Bangalore Rural District ( India ), Indian J Community Med, 40(2), 97-102.

Rausch, R. (2013). Nutrition and Academic Performance in School-Age Children The Relation to Obesity and Food Insufficiency. Journal of Nutrition $\mathcal{E}$ Food Sciences, 03(02), 3-5.

World Health Organization. (2019). Levels and trends in child malnutrition: key findings of the 2019 edition (No. WHO/NMH/NHD/19.20). World Health Organization.

World Health Organization. (2017). 2017 annual report WHO/UNICEF joint monitoring program for water supply, sanitation, and hygiene. In 2017 annual report WHO/UNICEF joint monitoring programme for water supply, sanitation and hygiene (pp. 20-20). 